\title{
Duodenogastric Reflux after Esophagectomy and Gastric Interposition
}

\author{
Naoki Hashimoto \\ Department of Surgery, Kinki University, Oosaka Sayama, Japan \\ Email:gojigen000@gmail.com
}

Received 8 June 2014; revised 19 July 2014; accepted 29 August 2014

Copyright (C) 2014 by author and OALib.

This work is licensed under the Creative Commons Attribution International License (CC BY). http://creativecommons.org/licenses/by/4.0/

(c) †) Open Access

\section{Abstract}

Stomach is considered the "gold standard" as an esophageal substitute after esophagectomy. Reflux disease is considered an unavoidable consequence of esophageal resection followed gastric interposition. Reflux esophagitis shows a progression from inflammation to erosions and to the development of columnar lined metaplasia. With the use of a gastric interposition, the most popular option to reconstruct the esophagus resected for malignant or benign conditions creates an in vivo model of reflux disease. Gastric interposition is far from ideal as an esophageal substitute. Reflux esophagitis and new columnar lined metaplasia should be seen as a new complication of subtotal esophagectomy.

\section{Keywords}

Duodenogastric Reflux, Reflux Esophagitis, Esophagectomy, Gastric Interposition, Columnar Lined Metaplasia

Subject Areas: Gastroenterology \& Hepatology, Surgery \& Surgical Specialties

\section{Introduction}

Stomach is considered the "gold standard" as an esophageal substitute after esophagectomy [1]. Although the whole organ can be used, the most suitable approach for reconstruction is the formation of a gastric tube by resection of the less er curvature.

The substitute can be placed in the posterior mediastinum or in an extra-anatomical - most commonly retrosternal-position. Extra-anato mical esophageal reconstruction offers the advantage that a recurrent intrathoracic tu mor mass will not invade the neo-esophagus [2] [3]. In addition, an extra-anato mical gastric interposition may also be used to bypass a corrosive esophageal injury.

Duodenogastric reflux (DGR) is a common sequel of gastric interposition and reflux symptoms adversely affect the quality of life of these patients. Furthermore, there is evidence that the duodenal contents are noxious 
and may, in the long term, cause mucosal changes both to the gastric conduit and the esophageal remnant [4] [5].

A number of reports show that esophagectomy and esophageal reconstruction with a gastric transplant are associated with a significant deterioration of quality of life that persists during the follow -up period [6] [7]. The aim of this work is to review the factors affecting a successful reconstruction of the esophagus when using the stomach, and the effect of the reconstruction on the esophageal remnant.

\section{Anatomical Consequences of Esophagectomy}

Anatomically, esophagectomy removes most of the esophagus with the proximal part of the stomach. For oncologic purposes, a rim of hiatal muscle is usually resected and left in continuity with the esophagogastric junction for an en bloc resection in the presence of malignancy. Every defense mechanis magainst reflu $\mathrm{x}$ is re moved with the resection. Duodenogastric reflu $\mathrm{x}$ is a common physiological sequel after esophagectomy with gastric conduit reconstruction [8]. Postprandial discomfort, bilious eructations, cervical burning and regurgitation, especially when in the supine position, are typical complaints these patients [9]. Reflux occurs principally because the normal antireflux mechanis ms have been resected or disrupted. Further, the pressure gradient between the intraabdominal duodenum (positive pressure) and intra-thoracic stomach (negative pressure), pro motes reflux [10]. The reconstruction then becomes a model of free duodenogastroesophageal reflux.

\section{Esophageal Exposure to Acid and Duodenal Juice}

Bilateral truncalvagotomy was the mainstay of treatment of duodenal ulcer disease, according to the principle of "no acid, no ulcer". The same procedure in relation to subtotal esophagectomy may dramatically impair acid secretion by the gastric transplant as an esophageal substitute at early follow-up as attested to by the reduction in both basal and peak acid outputs by $83 \%$ and 30\%, respectively [11]. Theoretically, gastric tubulization should reduce the parietal cell mass, further reducing the acid secretion capacity. However, despite the gastric conduit being vagotomized, the denervated stomach has been shown to recover its acid secretion capacity with time.

Gutshow et al. [11] noted that early after vagotomy intralu minal acidity decreased in two-thirds of the patients, but the stomach recovered its normal $\mathrm{pH}$ profile with time. They show that the denervated stomach as an esophageal substitute recovers a normal intralu minal acidity with time, so that more than 3 years after surgery. Hashimoto et al. [12] also noted that gastric acidity did not decrease after esophagectomy and the postoperative acidity in the gastric tube was high in patients with high preoperative acidity. Yuasa [13] suggested that the simu ltaneous analysis of $\mathrm{pH}$ and biliopancreatic reflux is useful for determining the cause of the severity of the mucosal damage in the esophageal remnant. The gastric transplant recuperates its acid production with time. Most of patients with a gastric interposition have biliopancreatic exposure in their transplant, the vast majority of these patients probably suffer from a mixed refluxate damaging their esophageal remnant. Mixed reflux is more harmful than acid reflux alone, suggesting synergistic mechanism of injury by acid and duodenalcontents [14].

\section{Mucosal Damage in the Esophageal Remnant}

The severity of mucosal damage in the esophageal remnant may progress from reflux esophagitis to columnar-lined metaplasia. Reflux esophagitis is significantly higher when documented by biopsies. When selecting patients with no endoscopic evidence of mucosal damage, 54\% of this subgroup presented with histologic abnormalities, usually basal cell hyperplasia and inflammatory infiltration of the mucosa. Thus the suggestion is strong that endoscopy and bipopsies are the most reliable methods to assess the esophageal remnant after a gastric transplant. Rakovich et al. [15] observed that even if no visual mucosal damage was evident, histological evidence of reflux insult could be documented in $75 \%$ of their patients. However, when endoscopic examination is used routinely after the operation, mucosal lesions are seen more often and they are usually more sever. The cervical esophagus is exposed to high amounts of acid despite the use of potent acid suppression therapy and the absence of sever symptoms. Esophageal columnar metaplasia is common complication after gastric pull up esophagectomy. The presence of abnormal bilirubin exposure was unrelated to the presence of esophageal columnar metaplasia but may be an important factor in the development of intestinal metaplasia. 


\section{Reflux Esophagitis}

A gastric tube has been widely used for reconstruction of the esophagus after esophagectomy for esophageal cancer. Reflux esophagitis after esophagectomy is frequent observed. Skinner [16] showed that the incidence of esophagitis after esophagectomy was higher than $30 \%$ when the stomach was used as a substitute for the esophagus. Gutshow [11] showed that $38.5 \%$ of patients had reflux esophagitis in the remnant esophagus for three years or more after esophagectomy.

Using the Los Angels classification (Table 1), Shibuya observed sever esophagitis (grade C or D) in $75 \%$ of their patients [17]. In another series of 48 patients, Yamamoto [18] found reflux esophagitis in 27 of their 48 patients $(56.3 \%)$ and majority $(70 \%)$ had a Los Angeles C or D damage.

\section{Esophageal Motility}

The esophageal remnant shows little or no contractile function early after operation. Poor peristals is and slower propagation are observed later.

After esophagectomy, peristaltic waves of the residual esophagus were not observed in our experience. Mathew [19] examined motility in the esophageal remnant in the immediately postoperative period after esophagectomy. Peristals is was absent in all patients studied during ventilation and sedation in the intensive care unit. Early post-operative esophageal motility after esophageal anastomosis varied some what with the length of residual esophagus. With short lengths of residual es ophagus, no consistent motility pattern emerged. With longer lengths, early peristaltic activity was evident, but dimin ished over the first few post-operative days. Esophageal resection and anastomosis is associated with loss of peristalsis in the initial post-operative period.

\section{Gastric Motility and Delayed Gastric Emptying}

The gastric substitute can be made as a tube or can be kept as a whole. Motor function seems to recover better when reconstruction is made using the whole stomach: in this setting, a near normal fasting motility index is regained. The stomach used an esophageal substitute is a contractile organ, even though it is disconnected from the extrinsic innervations pathways after truncalvagotomy [20]. The denervated stomach as an esophageal substitute is a contractile organ that may even generate complete migrat ing motor complex. Motor recovery is better in the fasting than in the fed period, and it is more marked in whole stomach patients than in gastric tube patients.

Bilateral truncalvagotomy, on the other hand, disturbs the balance between the propulsive action of the gastric antrum and the resistance of the pylorus to the flow of contents from and to the duodenum [21]. This is further complicated by removing part of the lesser curvature. Truncalvagotomy is generally necessary while preparing the conduit and inevitably leads to diminished function. To create a tubularized stomach, extensive mobilization and dissection of the stomach must be carried out, which may also affect function. Gastric emptying is more often delayed than accelerated after esophagectomy, and the gastric transplant reacts poorly to food ingestion. When using the stomach as a transplant, the prevalence of gastric emptying problems varies from $15 \%$ to $30 \%$ [22], and its occurrence is multifactorial. When clinically significant delayed emptying occurs, it is associated with increased morbidity [23], and it is for this reason that the routine performance of a gastric emptying procedure is frequently adovocated.

Table 1. Incidence and severity of reflux esophagitis (according to the Los Angels classification).

\begin{tabular}{ccc}
\hline Grade of esophagitis & No. of patients $(\mathrm{n}=74)[17]$ & No. of patients $(\mathrm{n}=48)[18]$ \\
\hline No esophagitis & $21(28.4 \%)$ & $21(43.7 \%)$ \\
Esophagitis & $53(71.6 \%)$ & $27(56.3 \%)$ \\
Grade A & $8 / 53(15.1 \%)$ & $2 / 27(7.4 \%)$ \\
Grade B & $5 / 53(9.4 \%)$ & $6 / 27(22.2 \%)$ \\
Grade C & $23 / 53(43.4 \%)$ & $17 / 27(62.9 \%)$ \\
Drade D & $17 / 53(32.0 \%)$ & $2 / 27(7.4 \%)$ \\
\hline
\end{tabular}




\section{Pyloric Drainage Procedure}

The significance and value of adding a pyloroplasty or a pyloro myotomy at the end of the interposed stomach is still debated [24]. On one hand, it may facilitate gastric emptying, thus favoring a reduced exposure to reflux. In Yajima's study [25], pyloroplasty was the only important risk factor according to univariate and multivariate analysis (relative risk 2.52; 95\% confidence interval $1.29-4.96 ; \mathrm{P}=0.007$ ). Py loroplasty can lead to bile reflux to the cervical remnant through the gastric tube in the long term, and thereby lead to reflux esophagitis in the cervical remnant. In fact, Urschel et al. [24] reported that pyloroplasty reduces the occurrence of early postoperative gastric outlet obstruction, but it has little effect on the patient's late outcome. On the other hand, pyloroplasty may also pro mote duodenal reflux and, in turn, facilitate the formation of the damaging reflu xate containg pancreato-biliary secretions mixed with gastric acid secretions.

\section{Level of Anastomosis (Left Cervical Anastomosis or Intrathoracic Anastomosis)}

An anastomosis below the level of the aortic arch was thought to be "reflexogenic", while one at the supra-aortic level was less so [26]. The physiologic explanation for this is that with a lower anastomosis, more of the stomach is subject to positive intra-abdominal pressure, which promotes greater reflux [27]. In addition, the results of Kim's study [28] showed that the incidence of reflux esophagitis was significantly lower in the cervical anastomosis group. Cervical anastomosis have shorter proximal esophageal segments compared to the longer intrathoracic segments, which are subject to weakened propulsion. Pulling the stomach all the way up to the neck abolishes the effect of positive intaabdominal pressure squeezing the fluids upward. The presence of the anastomotic line in the neck does not expose it to the negative pressure that enhances the development of reflux. Therefore, a left cervical anastomosis favors less mucosal damage compared to an intrathoracic reconstruction.

The incidence of reflux esophagitis in Shibuya's data [17] with a neck anastomosis (54.6\%) was significantly lower than in the patients with an intrathoracic anastomosis (88.6\%) (Table 2). This finding was in agreement with those of previous reports. Demeester et al. [29] stated that it was generally accepted that an esophagogastric anastomosis at the level of the neck resulted in less postoperative esophagitis and stricture formation than one performed within the chest. Although gastric advancement is the best method of reconstruction after esophagectomy from the viewpoint of safety and ease, an intrathoracic stomach is a poor long-term substitute. Esophagogastrostomy, independently of its location in the chest or in the neck is a model of gastroesophageal reflux. Esophagus and stomach become a common cavity and over time histologic evidence of re flu x lesions will affect the mucosa of the esophageal remnant. The cervical reconstruction may delay the appearance of visual mucosal lesions in the esophageal remnant. However, submucosal inflammation, mucosal-breaks and columnar lined metaplasia will eventually appear in a high proportion of patients.

Skinner [15] showed that stomach should not be used for reconstruction in patients with benign disease because of the high incidence of late esophagitis due to reflux and the risk of serious aspiration pneumonia. In addition, Demeester and collegues [29] also suggested that in patients with benign disease a colon interposition is usually preferred to obviate the late problems associated with a cervical esophagogastorostomy because patients undergoing a cervical esophagogastrostomy for benign disease may develop problems as sociated with the anastomosis during the fourth or fifth postoperative year, whereas this is less likely to develop in patients who have had a colon interposition.

For that reason, gastric advancement might be avoided for reconstruction after esophagectomy in these patients who are expected to survive long or who have benign disease, if possible. Therefore, I reco mmend a colon interposition for reconstruction after esophagectomy in these patients. The advantage of this reconstruction are it provides a good length of graft, and it allows a tube of a good diameter. The use of a colonic interposition

Table 2. Incidence of reflux esophagitis with neck and intrathoracic anastomosis [17].

\begin{tabular}{ccc}
\hline & Reflux esophagitis $(+)$ & Reflux esophagitis $(-)$ \\
\hline Intrathoracic & $31(88.6 \%)$ & $4(11.4 \%)$ \\
$(\mathrm{n}=35)$ & $22(56.4 \%)$ & $17(43.6 \%)$ \\
Neck & & \\
$(\mathrm{n}=39)$ & & \\
\hline
\end{tabular}


reduces the incidence of reflux esophagitis and stricture associated with esophagectomy. A previous report [30] showed that colon interposition with preservation of the stomach was superior to gastric pull-up for an esophageal substitute in quality of life. Udagawa et al. [31] also demonstrated that colon interposition as an esophageal substitute reduced the occurrence rate of anastomotic leakage and conduit necrosis to very low levels. However, this procedure is less safe and less easy to perform than gastric advancement.

\section{Route of Reconstruction (Posterior Mediastinum and Retrosternal Position)}

Despite the disruption of normal antireflux mechanism, the route of reconstruction may affect the esophageal exposure to gastric and duodenal content. Katsoulis [32] used 24 hour ambulatory bilirubin monitoring in patients following a transhiatal subtotal esophagectomy, and a gastric tube interposition placed either in the posterior mediastinum or in the retrosternal position. Posterior mediastinal gastric interposition is associated with high reflux of duodenal contents, whereas retrosternal interposition minimizes the reflux at levels even lower than those of the healthy individuals. The latter type of reconstruction may be a good alternative from that perspective, especially in patients with long life expectancy. In Wang's study [33], patients in posterior mediastinum group complained more DGR than retrosternal group after operation. Moreover, this difference became more and more evidently during the follow-up, especially after the $12^{\text {th }}$ week. The posterior mediastinum route theoretically has the disadvantage of the compression on the lung by the dilatation of the stomach with air and or digestive solution to increase the possibility of pulmonary implications. In their study, the patients in posterior med iastinum group complained more dyspnoea problem after operation, especially in later period (12 weeks after operation). C H Park et al. [34] established a method to observe and measure DGR inside the intrathoracic stomach as an esophageal substitute by devising the flow visualization model. They have demonstrated that the degree of DGR was significantly higher in the intrathoracic stomach located in posterior mediastinum being performed in the fluid mechanis $\mathrm{m}$. Thus, it is suggested that retrosternal route may be better choice for the $\mathrm{pa}-$ tients with poor respiratory function. Therefore, the reconstruction of retrosternal route may be suitable for the patients with long life expectancy.

\section{Conclusions}

Esophagogastrostomy, independently of its location in the chest or in the neck is a model of gastroesophageal reflux. Esophagus and stomach become a common cavity and over time histologic evidence of reflux lesions will affect the mucosa of the esophageal remnant. The cervical reconstruction may delay the appearance of $v$ is $u-$ al mucosal lesions in the esophageal remnant. Posterior mediastinal gastric interposition is associated with high reflux of duodenal contents, whereas retrosternal interposition minimizes the reflux at levels even lower than those of the healthy individuals. However, submucosal inflammation, mucosal-breaks, and columnar lined metaplasia will eventually appear in a high proportion of patients.

With the use of a gastric interposition, the most popular option to reconstruct the esophagus resected for malignant or benign conditions creates an in vivo model of reflux disease. Gastric interposition is far from ideal as an esophageal substitute. Reflux esophagitis and new columnar lined metaplasia should be seen as a new complication of subtotal esophagectomy.

\section{References}

[1] Akiy ama, H. (1990) Surgery for Cancer of the Esophagus: Reconstruction of the Esophagus. William and Wikins, Baltimore, 56-60.

[2] Gawad, K.A., Hosch, S.B. and Bumann, D. (1999) How Important Is the Route of Reconstruction after Esophagectomy: Prospective Randomized Study. American Journal of Gastroenterology, 94, 1490-1496. http://dx.doi.org/10.1111/j.1572-0241.1999.01131.x

[3] Van Lanschot, J.J.B., van Blankestein, M. and Oeis, H.Y. (1999) Randomized Comparison of Prevertebral and Retrosternal Gastric Tube Reconstruction after Resection of Esophageal Carcinoma. British Journal of Surgery, 86, $102-108$ http://dx.doi.org/10.1046/j.1365-2168.1999.00981.x

[4] de Martinez Haro, L., Ortiz, A. and Parrill, P. (2001) Intestinal Metaplasia in Patients with Columnar Lined Esophagus Is Associated with High Levels of Duodenogastroesophageal reflux. Annals of Surgery, 233, 34-38. http://dx.doi.org/10.1097/00000658-200101000-00006 
[5] Byrne, J.P. and Attwood, S.E.A. (1999) Duodenogastric Reflux and Cancer. Hepato-Gastroenterology, 46, 74-85.

[6] Egberts, J.H., Schniewind, B. and Bestmann, B. (2008) Impact of the Site of Anastomosis after Oncologic Esophagectomy on Quality of Life-A Prospective, Longitudinal Outcome Study. Annals of Surgical Oncology, 15, 566-575. http://dx.doi.org/10.1245/s10434-007-9615-1

[7] Blazeby, J.M., Metcalfe, C., Nicklin, J. and Barham, C.P. (2005) Association between Quality of Life Scores and Short-Term Outcome after Surgery for Cancer of the Esophagus Or Gastric Cardia. British Journal of Surgery, 92, 1502-1507. http://dx.doi.org/10.1002/bjs.5175

[8] Dresner, S.M., Griffin, S.M. and Wayman, J. (2003) Human Model of Duodenogastro-Esophageal Reflux in the Development of Barrett's Metaplasia. British Journal of Surgery, 90, 1120-1128. http://dx.doi.org/10.1002/bjs.4169

[9] Chattopadhyay, T.K., Shad, S.K. and Kumar, A. (1993) Intragastric Bile Acid and Symptoms in Patients with an Intrathoracic Stomach after Esophagectomy. British Journal of Surgery, 80, 371-373. http://dx.doi.org/10.1002/bjs.1800800336

[10] Malagelada, J.R., Ree, W.D.W. and Mazzotta, L.J. (1980) Gastric Motor Abnormalities in Diabetic and Postvagotomy gastroparesia: Effect of Metoclopramide and Betanechol. Gastroenterology, 8, 286-293.

[11] Gutschow, C., Collard, J.M., Romagnoli, R., Salizzoni, M. and Hölscher, A. (2001) Denerved Stomach as an Esophageal Substitute Recovers Intraluminal Acidity with Time. Annals of Surgery, 233, 509-514. http://dx.doi.org/10.1097/00000658-200104000-00005

[12] Hashimoto, M., Imamura, M., Shimada, Y., Shirakata, Y. and Takeuchi, K. (1995) Twenty-Four Hour Monitoring of $\mathrm{pH}$ in the Gastric Tube Replacing the Resected Esophagus. Journal of the American College of Surgeons, 180, 666672.

[13] Yuasa, N., Sasaki, E., Ikeyama, T., Miyake, H. and Nimura, Y. (2005) Acid and Duodenogastroesophageal Reflux after Esophagectomy with Gastric Tube Reconstruction. American Journal of Gastroenterology, 100, 1021-1027. http://dx.doi.org/10.1111/j.1572-0241.2005.41109.x

[14] Vaezi, M.F. and Richter, J.E. (1996) Role of Acid and Duodenogastroesophageal Reflux in Gastroesophageal Reflux Disease. Gastroenterology, 111, 1192-1199. http://dx.doi.org/10.1053/gast.1996.v111.pm8898632

[15] Rakovich, G., Brigand, C. and Gaboury, L. (2007) The Esophageal Remnant after Gastric Interposition (Abstract). French Society of Thoracic and Cardiovascular Surgery, Besancon. J Chir Thor Card Vasc, June, 258-259.

[16] Skinner, D.B. (1980) Esophageal Reconstruction. American Journal of Surgery, 139, 810-814. http://dx.doi.org/10.1016/0002-9610(80)90387-6

[17] Shibuya, S., Fukudo, S., Shineha, R., Miyazaki, S., Miyata, G., Sugawara, K., et al. (2003) High Incidence of Reflux Esophagitis Observed by Routine Endoscopic Examination after Gastric Pull-Up Esophagectomy. World Journal of Surgery, 27, 580-583. http://dx.doi.org/10.1007/s00268-003-6780-7

[18] Yamamoto, S., Makuuchi, H., Shimada, H., Chino, O., Nishi, T., Kise, Y., Kenmochi, T. and Hara, T. (2007) Clinical Analysis of Reflux Esophagitis Following Esophagectomy with Gastric Tube Reconstruction. Journal of Gastroenterology, 42, 342-345. http://dx.doi.org/10.1007/s00535-007-2011-6

[19] Mathew, G., Myers, J.C., Watson, D.I., Devitt, P.G. and Jamieson, G.G. (1999) Motility across Esophageal Anastomosis after Esophagectomy or Gastrectomy. Diseases of the Esophagus, 12, $276-282$. http://dx.doi.org/10.1046/j.1442-2050.1999.00072.x

[20] Mroz, C.T. and Kelly, K.A. (1977) The Role of Extrinsic Antral Nerves in the Regulation of Gastric Emptying. Surgery, Gynecology \& Obstetrics, 145, 369-377.

[21] Keane, F.B., Dimagno, E.P. and Malagelada, J.R. (1981) Duodenogastric Reflux in Humans: Its Relationship to Fasting Antroduodenal Motility and Gastric, Pancreatic and Biliary Secretion. Gastroenterology, 81, 726-731.

[22] Lee, H.S., Kim, M.S., Lee, J.M., Kim, S.K., Kang, K.W. and Zo, J.I. (2005) Intrathoracic Gastric Emptying of Solid Food after Esophagectomy for Esophageal Cancer. Annals of Thoracic Surgery, 80, 443-447. http://dx.doi.org/10.1016/j.athoracsur.2005.02.049

[23] Aly, A. and Jamieson, G.G. (2004) Reflux after Esophagectomy. British Journal of Surgery, 91, 137-141. http://dx.doi.org/10.1002/bjs.4508

[24] Urschel, J.D., Blewett, C.J., Young, J.E., Miller, J.D. and Bennett, W.F. (2002) Pyloric Drainage or No Drainage in Gastric Reconstruction after Esophagectomy: A Meta-Analysis of Randomized Controlled Trials. Digestive Surgery, 19, 160-164.

[25] Yajima, K., Kosugi, S.I., Kanda, T., Matsuki, A. and Hatakeyama, K. (2009) Risk Factors of Reflux Esophagitis in the Cervical Remnant Following Esophagectomy with Gastric Tube Reconstruction. World Journal of Surgery, 33, 284289. http://dx.doi.org/10.1007/s00268-008-9856-6

[26] Borst, H.G., Dragojevic, D., Stegmann, T. and Hetzer, R. (1978) Anastomotic Leakage, Stenosis, and Reflux after 
Esophageal Replacement. World Journal of Surgery, 2, 861-864. http://dx.doi.org/10.1007/BF01556541

[27] Bemelman, W.A., Verburg, J., Brummelkamp, W.H. and Klopper, P.J. (1988) A Physical Model of the Intrathoracic Stomach. American Journal of Physiology, 254, G168-G175.

[28] Kim, H.K., Choi, Y.H., Shim, J.H., Cho, Y.H., Baek, M.J., Sohn, Y.S. and Kim, H.J. (2008) Endoscopic Evaluation of the Quality of the Anastomosis after Esophagectomy with Gastric Tube Reconstruction. World Journal of Surgery, 32, 2010-2014. http://dx.doi.org/10.1007/s00268-008-9664-Z

[29] Demeester, T.R., Johansson, K.E., Frantze, I., Eypasch, E., Lu, C.T., McGill, J.E. and Zaninotto, G. (1988) Indications, Surgical Technique, and Long-Term Functional Results of Colon Interposition or Bypass. Annals of Surgery, 208, 460474. http://dx.doi.org/10.1097/00000658-198810000-00008

[30] Metzger, J., Dogen, I., Beglinger, C., von Flüe, M. and Harder, F. (1999) Clinical Outcome and Quality of Life after Gastric and Distal Esophagus Replacement with an Ileocolon Interposition. Journal of Gastrointestinal Surgery, 3, 383-388. http://dx.doi.org/10.1016/S1091-255X(99)80054-7

[31] Mine, S., Udagawa, H., Tsutsumi, K., Kinoshita, Y., Ueno, M., Ehara, K. and Haruta, S. (2009) Colon Interposition after Esophagectomy with Extended Lymphadenectomy for Esophageal Cancer. Annals of Thoracic Surgery, 88, 16471653. http://dx.doi.org/10.1016/j.athoracsur.2009.05.081

[32] Katsoulis, I.E., Robotis, I., Kouraklis, G. and Yannopoulos, P. (2005) Duodenogastric Reflux after Esophagectomy and Gastric Pull-Up: The Effect of the Route of Reconstruction. World Journal of Surgery, 29, 174-181. http://dx.doi.org/10.1007/s00268-004-7568-0

[33] Wang, H., Tan, L.J., Feng, M.X., Zhang, Y. and Wang, Q. (2011) Comparison of the Short-Term Health-Related Quality of Life in Patients with Esophageal Cancer with Different Routes of Gastric Tube Reconstruction after Minimally Invasive Esophagectomy. Quality of Life Research, 20, 179-189. http://dx.doi.org/10.1007/s11136-010-9742-1

[34] Park, C.H., Lee, J.I., Sung, J., Choi, S. and Ko, K.P. (2013) A Flow Visualization Model of Duodenogastric Reflux after Esophagectomy with Gastric Interposition. Journal of Cardiothoracic Surgery, 8, 192.

http://dx.doi.org/10.1186/1749-8090-8-192 